\title{
Pílula do Dia Seguinte: uma revisão de literatura sobre a Anticoncepção de Emergência
}

\section{Day after Pill: a review of literature about Emergency Anti-conception}

\section{Artigo \\ Original}

\section{Original \\ Paper}

\section{Rozana Aparecida de Souza ${ }^{1}$}

\section{Palavras-chaves:}

Anticoncepção

de Emergência

Saúde

Reprodutiva

Planejamento

Familiar

\section{Resumo}

Este artigo é uma revisão da literatura sobre o debate contemporâneo travado acerca da anticoncepção de emergência (AE), método contraceptivo comumente conhecido como pílula do dia seguinte.. A AE é um método normatizado pelo Ministério da Saúde desde 1996 para se evitar uma gravidez indesejada, tem seu uso recomendado em situações de emergência, como em casos de violência sexual, relação sexual desprotegida e nos casos de possível falha de outro método (ex: ruptura de camisinha). Foram levantadas pesquisas e estudos nacionais e internacionais sobre os mitos e barreiras que envolvem o acessso e o uso deste contraceptivo. $\mathrm{O}$ artigo apresenta um resgate sobre a história da contracepção no Brasil e sobre a constituição das políticas públicas de atenção integral a saúde da mulher, localizando a AE nestes contextos, bem como dados relevantes das pesquisas levantadas.

\begin{abstract}
This article is a literature revision about the contemporary debate about the emergency anti-conception (EA), a contraceptive method usually called the Day After pill. EA is a method regulated by Health Ministry since 1996 to avoid an undesirable pregnancy, it has its use recommended in emergency situations, as sexual violence, unprotected sexual relation and in cases of possible failure of another method (i.e. rupture of condom). National and International researches and studies about miths and barriers which involve the access and the use of the contraceptive method were considered. The article presents a return about the History of contraception in Brazil and about the constitution of public policies of integral attention to women health, observing EA in these contexts, as well as relevant data from the researches observed.
\end{abstract}

Key words:

Emergency Anti-conception

Reproductive

Health

Familiar

Planning.

\section{Introdução}

Pensar a Anticoncepção de Emergência (AE) e o debate contemporâneo travado em torno deste método contraceptivo impõe a necessidade de: refletir sobre os conceitos de gênero e sexualidade numa perspectiva socioantropológica; apresentar um breve resgate histórico sobre a contracepção, atentando para a constituição das políticas de controle de natalidade, bem como o posicionamento do movimento feminista em prol do reconhecimento da autonomia das mulheres; expor como a questão reprodutiva passou a fazer parte do cenário das políticas públicas, mas especificamente no campo das políticas de saúde; mostrar o processo de organização das ações de atendimento às questões reprodutivas em uma concepção de política de atenção integral à saúde da mulher, no campo dos direitos reprodutivos e sexuais.

Necessário se faz, também, discutir a política atual do Ministério da Saúde (MS) para os métodos contraceptivos, principalmente no

${ }^{1}$ Mestranda - Saúde Coletiva - IESC/UFRJ - Serviço Social UniFOA 
que se refere à AE: sua introdução no leque de métodos anticoncepcionais modernos, sua normatização pelo Ministério, sua prescrição pelos profissionais de saúde e sua distribuição aos serviços públicos de saúde, como parte das conquistas originárias do campo das políticas de direitos sexuais e reprodutivos do Brasil.

No sentido de apontar como a AE é percebida por vários segmentos da sociedade, resultados de pesquisas nacionais e internacionais foram elencados, nos quais ficam evidentes os mitos e barreiras que perpassam o acesso e o uso da pílula do dia seguinte.

\section{A História da Contracepção no Brasil}

A partir de 1950, várias foram as linguagens e conceituações relativas à saúde de mulheres e homens adotadas por vários países. Conceitos como controle de natalidade, controle populacional, planejamento familiar, saúde materno-infantil, saúde da mulher, saúde reprodutiva, saúde sexual, direitos reprodutivos, direitos sexuais, entre outros, indicam como os países têm trabalhado a questão do corpo, da reprodução e da sexualidade.

A atenção dada às questões populacionaistemevoluídoconsideravelmente, e mudanças têm sido incorporadas em políticas de diversos países. As décadas de 1950 e 1960 foram marcadas pela emergência de preocupações neomalthusianas de que o aumento populacional poderia atrasar o crescimento, destruir o meio ambiente, sucatear os serviços sociais e aumentar a pobreza. Para responder a essas preocupações, muitos países, nos anos de 1960, adotaram uma abordagem da questão populacional que envolvia uma política de controle de natalidade, implementando programas verticais de planejamento familiar. A idéia de que programas de planejamento familiar promoveriam o controle populacional, permaneceu ao longo da década de 1970. Formuladores de políticas defendiam a disseminação de métodos contraceptivos, mesmo que contrariassem os interesses individuais. Nos primórdios da demografia, preocupações com direitos individuais não eram incorporadas às análises da explosão populacional. (GALVÃO, 1999; CORRÊA et al.; 2006)
O Brasil apresentou um aumento populacional entre os anos de 1940 a 1970 . Segundo Vieira (2003), neste período, o país vivenciou uma alta na taxa de natalidade. Esta alta aconteceu graças a dois fatores: 1declínio moderado na taxa de mortalidade iniciado na década de 1940, devido ao controle de doenças transmissíveis e às melhorias no saneamento básico; 2- a alta da fecundidade. Essa fase produziu uma pirâmide etária com concentração em jovens.

A partir de 1970, o país mostra significativo declínio da fecundidade. O uso de métodos contraceptivos explica este declínio, considerado rápido e intenso. Segundo Berquó (apud Vieira, 2003), o Brasil demorou 40 anos para aumentar $45 \%$ na esperança de vida e 15 anos para diminuir $48 \%$ na taxa de fecundidade. Esta queda da fecundidade não foi resultado de nenhuma política nacional destinada a tal objetivo. Porém, segundo Vieira (2003), havia uma política implícita de controle populacional. Esta política colocava no mercado contraceptivos orais de baixo custo, facilitava o acesso à esterilização feminina e, também agia de forma indireta, através de ações de ampliação à educação, aumento das mulheres na força de trabalho e a promoção do consumo pela mídia televisa.

Sorj et al. (2007) explicam a rápida redução da fecundidade através de vários fatores, tais como: melhoria e popularização dos métodos contraceptivos, mudanças comportamentais relativas ao lugar da maternidade na identidade social das mulheres e, também o ingresso maciço das mulheres no mercado de trabalho (ocasionando menos prioridade para a formação de um núcleo familiar com filhos).

O tema planejamento familiar sempre levantou polêmicas no país. Durante a década de 1970, o debate em torno do controle demográfico encontravase acirrado e polarizado. O MS tratava a questão do planejamento familiar de forma pouco sistematizada. Antes de 1970, a baixa densidade demográfica provocava uma preocupação de ocupar todo o território nacional, principalmente as fronteiras. Havia também uma forte influência da Igreja Católica, para que não se adotasse políticas de planejamento familiar. (VIEIRA, 2003 ; COSTA et al., 2006).

Certos fatores contribuíram para 
mudanças no discurso do Estado acerca do planejamento familiar, a partir da década de 1970: o crescimento demográfico e a descrença em relação ao crescimento econômico frente a uma recessão mundial e pressões externas, levaram o governo brasileiro a assumir uma posição diferente. O Brasil passa a defender, em conferências e encontros internacionais, o direito dos casais ao planejamento familiar e o dever do estado em prover meios e informações sobre contracepção. Porém, nenhuma medida concreta foi tomada para implantar esta idéia.

Para Costa et al. (2006), esta atuação frágil do MS frente às ações de planejamento familiar, possibilitou que instituições de cunho controlista agissem em território nacional de forma desordenada. Vieira (2003) informa que proliferaram clínicas privadas de planejamento familiar e o comércio de contraceptivos no Brasil, já em 1965. Estas clínicas foram introduzidas por agências financiadas por órgãos internacionais, e eram denominadas controlistas por alinharem um discurso de controle de natalidade, almejando políticas de controle populacional e adotando metas demográficas, que incluíam o declínio da fecundidade. Tiveram maior relevância neste cenário a Sociedade Civil de Bem-Estar da Família no Brasil (BEMFAM) e o Centro de Pesquisas de Assistência Integrada à Mulher e à Criança (CPAIMC).

Para Vieira (2003), durante as décadas de 1960 e 1970, a questão do planejamento familiar, sempre foi controversa no cenário nacional, pois havia uma oposição clara por parte da Igreja Católica, por parte de intelectuais e acadêmicos, e faltava um consenso entre os grupos que formavam o governo militar. Segundo Costa et al. (2006) o governo brasileiro agiu de forma ambígua, tinha um posição de cautela em relação à política de controle da fecundidade, mas era permissivo acerca da atuação de entidades privadas.

O MS lançou, em 1977, o Programa de Saúde Materno-Infantil, que tinha por objetivo prevenir a gestação de alto risco. (CORRÊA et al., 2006). Até 1980, a política governamental para as mulheres se restringia a ações direcionadas à assistência ao pré-natal, parto e puerpério.

Este cenário abordado por Costa et al. (2006) e Vieira (2003), começou a mudar na década de 1980. Segundo as autoras, o início da década de 1980 foi marcado pela radicalização do discurso dos militares em relação ao controle demográfico. Esta radicalização foi acompanhada de uma reação indignada de novos atores sociais, dentre eles o movimento feminista, recente ainda no cenário nacional, mas com capacidade de introduzir neste debate posições firmes.

Os movimentos feministas criticavam a adoção de metas demográficas das entidades de planejamento familiar de cunho controlista, pois acreditavam que essas entidades queriam a todo custo aumentar o uso de contraceptivos para alcançar metas demográficas, porém, não apresentavam nenhuma preocupação com a saúde das mulheres. Duas idéias já se destacavam no país, através dos discursos dos movimentos feministas: a idéia do controle sobre o próprio corpo e sobre a reprodução e a questão da qualidade da assistência à saúde. $\mathrm{O}$ movimento feminista clamava pela autonomia das mulheres nas escolhas sobre procriação e contrapunha-se aos argumentos pró-natalistas de ocupação do território nacional. (ÁVILA e CORRÊA, 1999; VIEIRA, 2003).

\section{A Constituição das Políticas Públicas de Atenção Integral à Saúde da Mulher}

Segundo Costa et al. (2006), vale ressaltar que o posicionamento das mulheres, no cenário nacional, desde a década de 1960 , protagonizou uma ruptura com o clássico papel social da maternidade. As mulheres introduziram-se no mercado de trabalho, buscaram controlar a fecundidade e adotar práticas anticonceptivas e desvincularam a vida sexual da maternidade. A reprodução emergia como um tema a ser pensado para além das velhas práticas de controle de natalidade. Para Sorj et al. (2007) o que favoreceu a entrada das mulheres no mercado de trabalho foi a diminuição da taxa de fecundidade, bem como o crescimento da cultura de consumo.

A questão reprodutiva passou a fazer parte das políticas públicas, não como um direito geral, mas como um ponto específico no campo das políticas de saúde, a partir da década de 1980. (CORRÊA et al., 2006).

Em 1948, a Organização Mundial de Saúde (OMS) adotou um novo conceito de saúde amplo, multidimensional, que acabou por incluir a saúde reprodutiva: "saúde é 
um estado de completo bem-estar físico, mental e social e não meramente a ausência de doença ou enfermidade". A partir desta nova definição de saúde, foi-se delineando os conceitos de saúde materno-infantil, saúde da criança, saúde da mulher, etc.. (GALVÃO, 1999; CORREA et al., 2006).

Nos anos de 1980, a noção de "saúde integral da mulher" é adotada, mundialmente, a fim de articular aspectos relacionados à reprodução biológica e social, dentro dos marcos da cidadania. O termo "saúde da mulher”, não se restringia à reprodução, traduzia uma série de reivindicações: discriminação e legalização do aborto, acesso aos métodos contraceptivos, pré-natal e parto com qualidade, dentre outras reivindicações nos planos políticos e de atendimento médico (ÁVILA e CORRÊA, 1999; CORRÊA, et al., 2006).

Em 1983, o MS apresentou uma proposta de política concreta que concebia a questão da saúde da mulher de forma integral, não se detendo apenas nas questões de concepção e contracepção: o Programa de Atenção Integral à Saúde da Mulher - PAISM. O programa foi um marco pioneiro ao propor o atendimento à saúde reprodutiva no contexto da atenção integral e também por registrar o início da atuação do governo brasileiro nas questões relativas ao planejamento familiar. (Vieira, 2003; FIGUEIREDO, 2004; OSIS et al.,2006; COSTA et al.,2006; CORRÊA et al., 2006; GALVÃO, 1999).

Galvão (1999) chama atenção para o fato do conceito do PAISM ter se desenvolvido ao longo de anos, com base em experiências de programas do MS e de outras instituições, que eram realizadas no Brasil desde os anos de 1960.

O PAISM inovou no reconhecimento dos direitos reprodutivos das mulheres, ao contemplar vários aspectos da saúde reprodutiva feminina, abarcando todas as fases de vida da mulher, abandonando a visão reducionista da mulher apenas como mãe e reprodutora. Este novo programa incluía ações educativas, preventivas, de diagnóstico, tratamento e recuperação, englobando a assistência à mulher em clínica ginecológica, no pré-natal, parto e puerpério, no climatério, em planejamento familiar, DST, câncer de colo de útero e de mama, além de outras necessidades identificadas a partir do perfil populacional das mulheres (VIEIRA, 2003; FIGUEIREDO, 2004; COSTA et al., 2006).

Os direitos reprodutivos e sexuais, fazem parte de um conjunto mais amplo dos direitos humanos que, desde a Declaração Universal da ONU (1948), são considerados universais, indivisíveis, interdependentes e inter-relacionados. (CORRÊA et al., 2006). É importante não fundir a noção de direitos reprodutivos com direitos sexuais. $\mathrm{Na}$ sociedade atual, é preciso reconhecer que a atividade sexual não implica, necessariamente, em reprodução. Da mesma forma que reprodução nem sempre envolve atividade sexual, haja vista as técnicas de fertilização in vitro. Gênero, sexualidade e reprodução fazem parte da vida humana, que se tangenciam, que podem até se confundir, mas que correspondem a dimensões distintas.

Heilborn (1997) informa que a adoção do termo gênero surge nos anos de 1970, principalmente, graças à critica feminista. "Este conceito veio salientar a dimensão de atribuição cultural e modelação dos corpos sexuados". (HEILBORN, 2006, p. 34)

Para esta autora, é a cultura que constrói o gênero, simbolizando as atividades como masculinas ou femininas. A categoria esta profundamente relacionada à reprodução, pois tem sido reafirmado na literatura, que é no trabalho reprodutivo, o lugar onde a diferença se instala. Analisando o cenário contemporâneo, pode se afirmar que a "distribuição das tarefas entre os sexos é, em muitos sistemas culturais, entendida como espécie de extensão das diferenças anatômicas (procriativas) entre os sexos" (HEILBORN, 1997, p. 104). Portanto, "naturaliza-se" uma série de tarefas como eminentemente femininas, associadas ao papel que a mulher ocupa no processo produtivo: o cuidado com a prole é destinado às mulheres.

Segundo Bozon (2004), a maior parte das culturas traduziu a diferença dos sexos em uma linguagem binária e hierarquizada, na qual apenas um dos sexos era valorizado. Dentro desta lógica, o feminino esta assinalado no lado inferior.

Ainda segundo Bozon (2004), em todas as culturas, a iniciação sexual é uma etapa marcante para a construção social do masculino e do feminino. Para Heilborn (2006), as articulações entre gênero e sexualidade exprimem essa tensão. A sexualidade vem sendo entendida como produto de diferentes
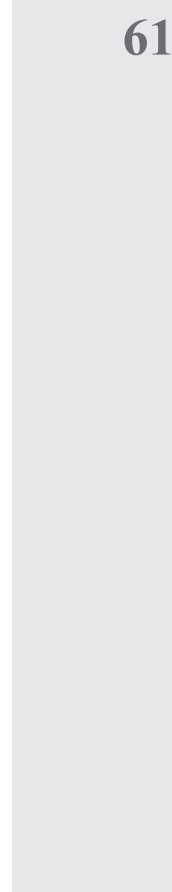
cenários, e não somente como derivada do funcionamento bio-psíquico dos indivíduos. $\mathrm{O}$ destaque sobre o cenário sociocultural remete à premissa de que, se há características distintas entre homens e mulheres no tocante à vida sexual e na interface desta com a esfera reprodutiva, elas ocorrem devido a uma combinação de fenômenos que refletem nos corpos como efeito de processos complexos de socialização dos gêneros. Portanto, há estrito imbricamento entre sexualidade gênero.

"A sexualidade seria uma forma moderna (sec. XVIII) de arranjo e construção de representações e atitudes sobre o que seria uma atitude erótica espontânea, traduzindo uma dimensão interna dos sujeitos, ordenadas pelo desejo" (HEILBORN, 1997, p. 105). Estudos sociológicos mostram que a construção social tem um papel central na elaboração da sexualidade humana. De acordo com Bozon (2004), a programação biológica continua predominante na sexualidade animal, enquanto que nos homens, devido ao processo de "educação", necessita de um aprendizado social para saber de que maneira, quando e com quem agir sexualmente.

$\mathrm{Na}$ contemporaneidade, a procriação ocupa apenas um espaço reduzido e marginal, enquanto que a sexualidade aparece como uma experiência pessoal, fundamental para a construção do sujeito, em um domínio que se desenvolveu e assumiu um peso considerável no decorrer dos séculos: a esfera da intimidade e da afetividade.

De acordo com Bozon (2004), o repertório sexual se ampliou, as normas e as trajetórias da vida sexual se diversificaram, os saberes e as encenações da sexualidade se multiplicaram. No mundo ocidental contemporâneo, a vida sexual não está mais identificada com a fecundidade e a procriação.

$\mathrm{O}$ fundamento dos direitos reprodutivos é a autonomia de decidir sobre a procriação. Uma questão importante sobre estes direitos se refere ao fato de que eles não devem se restringir às mulheres, mas também incluem os homens. As decisões reprodutivas devem ser conseqüência de consentimento mútuo entre os parceiros. (CORRÊA e PETCHESKY, 1996).

No processo de implantação do PAISM, prevaleceu o discurso consensual, baseado nos princípios do direito à saúde e na autonomia das mulheres e dos casais sobre o número de filhos que desejavam ter. Este discurso foi produto da reforma sanitária em curso no país. O PAISM incorporou, como princípios e diretrizes, as propostas de descentralização, hierarquização e regionalização dos serviços, bem como a integralidade e a eqüidade da atenção, num período em que, paralelamente, no âmbito do Movimento Sanitário, se concebia o arcabouço conceitual que embasaria a formulação do Sistema Único de Saúde (SUS) (GALVÃO, 1999; ÁVILA e CORRÊA, 1999; COSTA et al. 2006).

Em 1988, com a promulgação da Constituição Federal, torna-se visível uma das grandes conquistas do Movimento da Reforma Sanitária: a garantia da saúde como direito do cidadão e dever do Estado. O planejamento familiar também foi definido na Carta Magna como de livre arbítrio das pessoas envolvidas (COSTA et al., 2006). O direito ao planejamento familiar foi definido no $\S 7$ do Art. 226 da Constituição Federal de 1988:

Fundado nos princípios da dignidade da pessoa humana e da paternidade responsável, o planejamento familiar é livre decisão do casal, competindo ao Estado propiciar recursos para o exercício desse direito, vedada qualquer forma coercitiva por parte de instituições oficiais ou privadas.

A lei n. ${ }^{\circ} 9.263$, de 12/01/1996 - que regula o $\S 7^{\circ}$ do art. 226- define o planejamento familiar bem como a Portaria n. ${ }^{\circ} 144$, de 20/11/1997, da Secretaria de Assistência à Saúde/MS.

A Portaria $n^{\circ} 48$, de 11/02/1999, da Secretaria de Assistência à Saúde/MS, que também definiu o planejamento familiar, inova ao apontar normas e diretrizes para a realização da esterilização (tanto feminina quanto masculina).

O PAISM à época (1983), já havia estabelecido que o planejamento familiar deveria incluir ações para a anticoncepção e também atenção aos casos de infertilidade.

Umadécadadepois, algumaspesquisas de avaliação do PAISM foram produzidas. Uma delas (OSIS et al, 2006) identificou que sua implantação foi caracterizada pela descontinuidade e baixa efetividade das ações, e os avanços foram lentos durante os quinze anos que se seguiram. Apesar dos esforços do MS, os pontos cruciais do PAISM, ainda na 
década de 1980 eram: a disponibilidade dos métodos anticoncepcionais na ponta do sistema de saúde e a capacitação dos profissionais envolvidos na operacionalização das ações do programa. Para Galvão (1999), é importante reconhecer que as limitações e "fracassos" do PAISM não podem ser analisados de forma descontextualizada, mas considerando-se o quadro caótico em que se encontrava o sistema de saúde pública nacional, na década de 1980, e uma série de dificuldades culturais, políticas, sociais, econômicas que tornaram entraves para a operacionalização do conceito de saúde integral da mulher.

$\mathrm{Na}$ década de 1990, algumas mudanças foram encadeadas pelo Ministério, procedendo-se a descentralização de recursos federais, incluindo a compra de insumos contraceptivos. Apesar destas mudanças, os problemas com o planejamento familiar persistiram, como apontado nos dados do relatório técnico de uma missão enviada pelo Fundo de População das Nações Unidas (FNUAP).

Alguns dados deste relatório são destacados por Vieira (2003): havia uma grande lacuna entre a demanda das pessoas por contraceptivos e o desejo e acesso aos métodos anticoncepcionais; foi constatada falta de insumos contraceptivos e ausência de gerenciamento logístico; percebeu-se falta de capacidade técnica das equipes em clínicas dos serviços públicos. Este relatório concluiu que havia à disposição das mulheres apenas dois métodos contraceptivos (a pílula anticoncepcional e a esterilização), havia, também, uma distorção nos propósitos do programa que acabava por não contribuir com a saúde reprodutiva das mulheres.

No ano de 2000, o MS voltou a disponibilizar os insumos através das secretarias estaduais de saúde. A partir de algumas tentativas de avaliação deste sistema de distribuição de contraceptivos e de discussões sobre as políticas desta área, foi proposta uma nova estratégia, na qual a compra dos insumos e envio (trimestral) aos municípios ficaria a cargo do MS, com a meta de atender $30 \%$ da demanda. O envio era vinculado a algumas exigências: ter pelo menos uma equipe do Programa de Saúde da Família (PSF) habilitada ou; estar com o termo de adesão ao Programa de Humanização no Pré-Natal e Nascimento (PHPN) aprovado ou contar com pelo menos uma equipe do Programa de Interiorização do Trabalho em Saúde (PITS) (OSIS, 2006).

Essa nova estratégia para distribuição de métodos anticoncepcionais reversíveis era baseada, no envio de kits de contraceptivos: o básico (que era composto pela pílula combinada de baixa dosagem, a minipílula e o preservativo masculino) e o complementar (que era composto pelo Dispositivo Intra-Uterino -DIU- e pelo anticoncepcional injetável trimestral). Se o município tivesse condições adequadas para a prescrição e utilização de injetáveis e do DIU, era encaminhado, também, o kit complementar. (OSIS et al.,2006; OSIS, 2006)

No ano de 2002, foram realizadas 2 remessas para os municípios. Foi enviado um total de 40.000 kits básicos, para 4.568 municípios, e 2.659 kits complementares, para 433 municípios. Além destes kits, o MS, naquele ano, pela primeira vez, distribuiu a pílula anticoncepcional de emergência, para aproximadamente 439 municípios e 59 serviços de referência em atenção às mulheres vítimas de violência sexual.

Por ocasião do envio da primeira remessa de insumos aos municípios, em julho de 2002, o MS solicitou ao Centro de Pesquisas em Saúde Reprodutiva de Campinas (CEMICAMP), uma pesquisa com o objetivo de "verificar se os métodos anticoncepcionais enviados aos municípios estavam à disposição nas Unidades Básicas de Saúde, e identificar os possíveis obstáculos a essa disponibilidade" (OSIS et al., 2006: 2482).

Com a realização da pesquisa avaliativa, as pesquisadoras do CEMICAMP apontaram a seguinte questão: a atenção ao planejamento familiar continuava a ser marcada pela indisponibilidade de métodos anticoncepcionais nos serviços públicos de saúde e pela capacitação desigual e insuficiente dos profissionais para atuarem neste campo. Os profissionais das equipes de saúde da família não consideram o planejamento familiar como parte da atenção básica em saúde e não se julgavam capacitados para oferecer serviços assistência nesta área. Para resolver estas questões, as pesquisadoras chamam a atenção para o fato de que mesmo que o MS assegure a regularização da distribuição dos métodos às secretarias municipais de saúde, é mister que os municípios incorporem o planejamento 
familiar como uma ação de atenção básica, desenvolvendo as ações e atividades com base em princípios relativos aos direitos humanos $\mathrm{e}$ à bioética. Estas análises construídas sobre a trajetória do planejamento familiar no Brasil são relevantes para pensarmos sobre a eficácia desta política no país.

Segundo o Manual Técnico de Assistência em Planejamento Familiar (MINISTÉRIO DA SAÚDE, 2002), ainda hoje o quadro de uso dos métodos de anticoncepção reflete algumas distorções da oferta dos mesmos no território nacional desde a década de 1960, quando ela foi iniciada pelas entidades privadas de cunho controlista, tendo como métodos quase exclusivos a pílula e a laqueadura. Segundo Vieira (2003), as principais características do planejamento familiar seriam: a medicalização e a privatização.

A OMS, no mesmo ano da promulgação da Constituição Federal de 1988, adota a concepção de "saúde reprodutiva", visando incorporar dimensões sociais da reprodução e desenhar políticas que respondessem às necessidades como pré-natal, parto, puerpério, aborto, doenças ginecológicas e câncer cervical. Este conceito inovou ao incorporar os homens da dimensão reprodutiva. Porém, a expressão utilizada no Brasil continuou sendo "saúde integral das mulheres". (CORRÊA et al., 2006)

Segundo a Conferência Internacional sobre População e Desenvolvimento (1994), saúde reprodutiva pode ser definida como um estado de completo bem-estar físico, mental e social em todas as matérias concernentes ao sistema reprodutivo, suas funções e processos, e não apenas mera ausência de doenças ou enfermidade. A saúde reprodutiva implica que a pessoa possa ter uma vida sexual segura e satisfatória, tendo a capacidade de reprodução e a liberdade de escolher quando e quantas vezes desejar fazê-lo.

Vale ressaltar que após 14 anos desta conferência, o cenário nacional desenha um quadro onde: prevalece a atenção curativa à saúde, há restrições na liberdade de escolha dos sujeitos no que se refere à reprodução e há dificuldades de acesso aos métodos de contracepção, sendo que muitas vezes nem existe o acesso da população aos métodos contraceptivos.

Mais recentemente, o MS lançou em 2004, o documento "Política Nacional de Atenção Integral à Saúde da Mulher: Princípios e Diretrizes". Tal política foi construída nos anos de 2003 e 2004, em parceria com diversos setores da sociedade. Este documento reflete o compromisso com a implementação de ações de saúde que contribuam para a garantia dos direitos humanos das mulheres e reduzam a morbimortalidade por causas preveníveis e evitáveis. Esta política tomou como referência o conceito de saúde da OMS, incorporou princípios da saúde reprodutiva, bem como dimensões da sexualidade e da reprodução humana numa perspectiva de direitos (MINISTÉRIO DA SAÚDE, 2004a).

A Política Nacional de Atenção Integral à Saúde da Mulher apresentou um plano de ação/metas para os anos de 20042007 (MINISTÉRIO DA SAÚDE, 2004b), com 14 objetivos.

Em 2005, atendendo a um dos objetivos da Política Nacional de Atenção Integral à Saúde da Mulher, o MS lançou o documento "Direitos Sexuais e Reprodutivos" que, apresenta diretrizes para garantiros direitos de homens e mulheres, adultos e adolescentes em relação à saúde sexual e reprodutiva. Neste documento, o governo brasileiro assume compromisso com o respeito e a garantia dos direitos humanos, entre os quais os direitos reprodutivos, na formulação e implementação de políticas em relação ao planejamento familiar e toda e qualquer questão referente à população e ao desenvolvimento.

\section{A Pílula do Dia Seguinte}

No que concerne à anticoncepção, os serviços de saúde devem fornecer todos os métodos anticoncepcionais recomendados pelo MS, inclusive a AE. É importante mencionar que a $\mathrm{AE}$, também conhecida por pós-coital ou pílula do dia seguinte, é uma tecnologia aprovada pela Agência Nacional de Vigilância Nacional (ANVISA) e está inserida entre os recursos disponíveis às mulheres, que constam na Política Nacional de Saúde da Mulher do MS.

Este método de contracepção póscoito começou a ser estudado nas décadas de 1960 e 1970, pelo médico canadense Albert Yuzpe, como uma resposta médica para as conseqüências de uma violência 
sexual (MARTIN, 2004; CASTILLO, 2006), sendo sua eficácia conhecida há mais de trinta (30) anos (FIGUEIREDO, 2004; PINTO COSTA et al., 2008). Porém, ainda é uma opção de contracepção pouco utilizada para prevenir uma gravidez não planejada e morbimortalidade associadas ao abortamento inseguro, principalmente em países onde o aborto é considerado ilegal, como nos países da America Latina.

A $\mathrm{AE}$ foi reconhecida como medicamento essencial pela Organização Mundial de Saúde (OMS) em 1995, quando esta organização juntamente com mais seis instituições, que atuam em Saúde Sexual e Reprodutiva, formaram o Consórcio Internacional de Anticoncepção de Emergência (CLAE), com o objetivo de ampliar o acesso e o uso deste método. Instituições brasileiras, membros deste consórcio, foram as responsáveis por se criar condições viáveis, no cenário brasileiro, para mobilização, discussão e inclusão deste método no Manual de Assistência ao Planejamento Familiar do MS, em 1996. (PINTO COSTA et al., 2008)

Segundo Hardy et al. (2001), o Brasil apresenta um contexto jurídico e político favorável à AE deste 1996, quando este método (em regime de Yuzpe - combinado de pílulas orais comuns) foi incorporado a esse Manual. O documento foi fruto de uma oficina, promovida pelo escritório brasileiro do Population Council e pela Coordenação de Saúde Materno-Infantil do MS, realizada em Brasília, em março de 1996, que envolveu 28 profissionais brasileiros e estrangeiros. Os profissionais tinham por objetivo definir diretrizes para a introdução da $\mathrm{AE}$ na atenção a saúde reprodutiva no Brasil.

Também no ano de 1998, o MS editou uma Nota Técnica sobre a AE, que teve seu texto atualizado nos anos de 2005 e 2006. Esse documento se constitui em mais um instrumento para legalizar e legitimar a AE no cenário nacional. É mister informar que a Nota Técnica de 2006 vigora e trata da definição, mecanismo de ação, indicações de uso, prescrição, e outros esclarecimentos sobre a AE. (MINISTÉRIO DA SAÚDE, 2006)

O MS caracteriza o método da contracepção de emergência como um uso alternativo da anticoncepção hormonal oral para evitar gravidez depois da relação sexual desprotegida. O método deve ser usado até 72 horas após a relação sexual: a $1^{\mathrm{a}}$ dose até 72 horas e a $2^{\mathrm{a}}$ dose após 12 horas depois da $1^{\mathrm{a}}$ (MINISTÉRIO DA SAÚDE, 2002). Segundo Nogueira (2000), a eficácia do método pode diminuir, quando ingerida atrasada. Portanto, o quanto antes as mulheres tenham acesso a AE, maior será sua eficácia.

Para Nogueira et al (2000), os anticoncepcionais de emergência são métodos alternativos de anticoncepção para serem usados em situações, consideradas por estes autores como especiais: relação sexual desprotegida, não planejada; uso inadequado de métodos anticoncepcionais (por exemplo: esquecimento de duas ou mais pílulas de anticoncepcionais regulares); falha anticoncepcional presumida (acidentes com o uso do preservativo ou com o diafragma); violência sexual.

Alguns métodos, recomendados pelo MS, são utilizados com o fim de promover a contracepção pós-coital. Os mais utilizados são osquecombinamumaassociação de estrogênios e progestogênios, e/ou progestogênios puros. Outro combinado de hormônios comum é conhecido com regime de Yuzpe (o primeiro método a ser normatizado no Brasil pelo MS), realizado através de super dosagens de pílulas anticoncepcionais orais comuns a base de etinil-estradiol e levonorgestrel (NOGUEIRA et al., 2000; PINTO COSTA et al., 2008 ).

Dependendo da fase do ciclo menstrual em que é usado, o mecanismo de ação da $\mathrm{AE}$ pode interferir na ovulação (inibição ou atraso); com a nidação (provocando alterações na resposta endometrial) ou com a fecundação (alterando a função do corpo lúteo e a motilidade tubária) (MINISTÉRIO DA SAÚDE, 2002; NOGUEIRA et al., 2004; COSTA et al., 2008).

Nogueira et al. (2004) afirma que apesar da eficácia comprovada da $\mathrm{AE}$, quando iniciado o processo de nidação, o método perde o efeito e não há evidências de conseqüências nocivas para o quadro gestacional, incluindo para o embrião.

Concomitante às conquistas no campo da saúde reprodutiva, ganhos na área do combate à violência contra mulheres, concretizadas na década de 1990, também incorporaram a $\mathrm{AE}$ às normas técnicas para o atendimento às vítimas femininas de violência sexual. Em 1998, foi editada pelo MS a Norma Técnica Prevenção e Tratamento dos Agravos 
Resultantes da Violência Sexual contra Mulheres e Adolescentes. Porém, essa norma foi regulamentada apenas em 1999, após embates no Congresso Nacional, ocasionados por alguns parlamentares que a consideravam "legitimadora do aborto" (HARDY et al., 2001; FIGUEIREDO E PEÑA, 2002; FIGUEIREDO, 2004).

Esta norma sistematizou uma série de procedimentos para o atendimento dos casos de violência sexual: apoio psicológico; prevenção para a profilaxia de DSTs, incluindo HIV, e de prevenção à gravidez, com a administração da AE na forma de Yuzpe.

Em 2000, o Ministério da Saúde iniciou suas primeiras aquisições de $\mathrm{AE}$ que foram enviadas aos Serviços de Atendimento às Vítimas de Violência, atendendo assim a norma técnica.

No ano de 2005, o governo federal resolveu ampliar em 57\% a distribuição da $\mathrm{AE}$ nos serviços públicos, com a intenção de fornecer a chamada pílula do dia seguinte a todas as mulheres, não somente às vítimas de violência sexual. Esta medida fazia parte da política de direitos sexuais e reprodutivos do MS, cujo foco era garantir a autonomia no planejamento familiar. $\mathrm{O}$ documento determina que a pílula do dia seguinte deveria ser fornecida a todas as mulheres, de modo que não ficasse restrita apenas aos serviços de referência para vítimas femininas de violência sexual. (SUWWAN, 2005)

Para Figueiredo (2004), os serviços de saúde pública no Brasil não acataram as normas de 1996 e de 1998, pois não foram iniciados os processos de divulgação, de fornecimento e de administração do método. Exceção a esta regra, foram os serviços de atendimento as vítimas de violência sexual que mantiveram a implementação da normatização de 1998 e persistiam na luta pela difusão e disponibilização do método.

Setores sociais conservadores têm, publicamente, criticado as propostas da Política Nacional de Direitos Sexuais e Direitos Reprodutivo, favorecendo, inclusive, a elaboração de legislações por Câmaras Municipais, que sejam impeditivas do exercício dos direitos sexuais e reprodutivos e da implantação das diretrizes governamentais, em claro desrespeito ao ordenamento jurídico nacional. Dois fatos ocorridos no interior de São Paulo exemplificam este desrespeito às diretrizes nacionais: a Câmara Municipal de São José dos Campos, que em 2005 proibiu a distribuição da $\mathrm{AE}$ recebida pelo $\mathrm{MS}$, e a Câmara Municipal de Jundiaí, que no ano de 2008 também proibiu a utilização da AE no município.

O Conselho Federal de Medicina (CFM) publicou, em 14 dezembro de 2006, a resolução 1811 a fim de estabelecer normas técnicas para o uso da AE. Este documento considera que a pílula do dia seguinte não é abortiva e pode ser usada em qualquer idade; fundamentando-se nos direitos reprodutivos, na responsabilidade do estado em implementar estes direitos, no número expressivo de mulheres que estão sujeitas a gestações não planejadas, e no fato dos adolescentes e jovens serem os mais propícios a estas gestações.

Esta resolução pode ser considerada um desdobramento do Fórum 2005: Adolescência e Contracepção de Emergência, realizado na cidade de São Paulo. O evento foi organizado pela Unidade de Adolescentes do Instituto da Criança do Hospital das Clínicas da Universidade de São Paulo(USP). Participaram pediatras, ginecologistas, profissionais ligados a Comissões de Bioética, ao Conselho Federal de Medicina e ao MS. Para oferecer respaldo aos debates foram escolhidos advogados e juízes e demais representantes da Justiça. (SAITO e LEAL, 2007)

O Fórum 2005 teve como proposta trazer maiores esclarecimentos sobre a $\mathrm{AE}$, apoio técnico e ético para a prescrição deste método. Como resultado, foi definido que a educação sexual (como prática preventiva) é uma política relevante para a adolescência. A orientação anticoncepcional, incluindo a contracepção de emergência, é parte importante desta política. Foi reconhecido o direito de o adolescente ter acesso a informação sobre todos os métodos. O Fórum discutiu e elaborou estratégias para facilitar e ampliar o acesso dos adolescentes a AE. (SAITO e LEAL, 2007)

Dados do MS apontam que a taxa de fecundidade entreadolescentes têmaumentado, desde os anos de 1990 cresceu 26\%. Este aumento é contrário à realidade nacional das taxas de fecundidade entre mulheres adultas: em 1940, a média nacional era 6,2 filhos, no ano 2000 caiu para 2,3 filhos. Em geral, a gravidez na adolescência é considerada um risco para a saúde do adolescente e um fato desestabilizador da vida de adolescentes. 
São muitas as causas para este fenômeno da gravidez em tenra idade, porém, em muitos casos, ela está relacionada com situações de vulnerabilidade social, falta de informação e acesso a serviços de saúde, e ao baixo status de adolescentes mulheres em relações sociais vigentes. Ao mesmo tempo em que nesta faixa etária, a gravidez pode estar relacionada com o desejo de ser mãe. (MINISTÉRIO DA SAÚDE, 2007).

Reconhecer que o adolescente tem o desejo de engravidar, não significa deixar de investir em políticas de contracepção, uma vez que o direito de escolha e de planejamento tem que ser assegurado. Portanto, é preciso garantir os direitos reprodutivos a adolescentes e jovens de maneira irrestrita. acatando-se as diretrizes elaboradas no Fórum 2005: Adolescência e contracepção de emergência. (MINISTÉRIO DA SAÚDE, 2007).

A AE faz parte de uma proposta pediátrica de prevenção de problemas ou agravos a saúde. Afirmação que pode ser comprovada através do percentual de gestações não planejadas na adolescência que evoluem para o aborto: $25 \%$ das gestações não planejadas. (Saito e Leal, 2007). Calcula-se que no Brasil, no mínimo, 25\% das gestações são indesejadas. Dos nascidos vivos registrados, aproximadamente $22,63 \%$ são filhos de meninas entre 15 e 19 anos. (MINISTÉRIO DA SAÚDE apud FIGUEIREDO, 2004).

Para o MS a prescrição da AE, nas situações de exposição ao risco iminente de gravidez (violência sexual, falha do método em uso ou na sua utilização, não estar usando anticoncepcional), se constitui dever do médico e um direito do adolescente.

O uso da pílula de AE no Brasil, mesmo com todas as diretrizes do MS e do CFM, vem ocorrendo há anos em ambientes restritos, não se constituindo como uma prática sistematizada. A prescrição deste método pelos profissionais de saúde, tanto no setor público quanto no setor privado, ainda é bastante restrita e mistificada. (HARDY et al. 2001; OSIS et al., 2006).

Atualmente, existem setes

marcas comerciais deste produto no país. Em setembro de 1999, a primeira marca comercial de $\mathrm{AE}$ em dose única (duas pílulas de 750 microgramas de levonorgestrel) foi introduzida no mercado brasileiro. Segundo Figueiredo (2004), a facilidade de aquisição do método em farmácias para a compra, (uma vez que a necessidade de prescrição médica regulamentada pela Vigilância Sanitária, não é respeitada), promoveu a reatualização do debate sobre o acesso ao contraceptivo.

Problemas culturais e informações distorcidas sobre AE constituem barreiras para sua aceitação, acesso e uso adequado, apesar do contexto jurídico e político brasileiro ser favorável à AE e a sua comercialização. Vários estudos foram realizados no Brasil nos últimos anos com o objetivo de conhecer os mitos e as barreiras que envolvem o acesso e o uso da AE. (NOGUEIRA et al.,2000; HARDY et al., 2001; DIAZ et al. 2003a; DIAZ et al. 2003b; OSIS et al., 2006; OSIS, 2006; PINTO COSTA, 2008).

O trabalho de introduzir efetivamente a AE no Brasil, assim como nos países da América Latina e Caribe, tem sofrido ataques da Igreja Católica e de grupos de direita. Mesmo o Brasil se constituindo uma exceção por ter a $\mathrm{AE}$ incorporada às normas do MS, entidades ligadas à Igreja Católica têm se oposto de várias formas para impedir que o uso da contracepção pós-coito se legitime no país. Outros países latinos sofrem a mesma interferência do poder religioso nas decisões do Estado, que a priori deveriam ser laicas. A idéia de que a AE é abortiva tem grande peso na América Latina, principalmente porque muitas sociedades são conservadoras e a Igreja Católica tem grande influência. (MARTIN, 2004; FAÚNDES et al.,2007)

A Igreja Católica, ao longo de sua história vem interferindo nos assuntos ligados à reprodução e à sexualidade. Tendo por princípio o sexo para a procriação, a igreja não admite comportamentos diferentes da sua norma, até mesmo para as pessoas que não são adeptos de sua doutrina. Apesar de todas as mudanças e transformações pelas quais passaram o comportamento social de homens e mulheres, a igreja tem obtido êxito com seu discurso conservador sobre a sexualidade e a família na elaboração de políticas públicas latinas (ÁVILA e CORRÊA, 1999 ; CASTILLO, 2006).

A Igreja Católica tem ignorado todas as provas científicas de que o mecanismo de ação da AE não interfere na implantação do óvulo fecundado, e mantém o discurso de que tal método provocaria aborto precoce, pois teria uma ação de interferência na implantação 
do óvulo fecundado. O padrão de oposição católico à $\mathrm{AE}$ tem sido o mesmo em toda a região latina (FAÚNDES et al., 2007).

Pensamento semelhante é percebido entre muitos provedores de serviços de saúde e em determinados setores da população, que acabam provocando problemas quanto à distribuição da AE. Segundo diversos estudos realizados em países latinos, esta errônea percepção estaria vinculada a poucos (ou a nenhum) investimentos em capacitações para profissionais envolvidos na prescrição e na disponibilização do método; bem como nas campanhas de informação para as possíveis usuárias sobre o mecanismo de ação $\mathrm{e}$ os benefícios deste método (DÍAZ et al., 2003a; DÍAZ et al., 2003b; MARTIN, 2004; FAÚNDES et al., 2007).

Um forte opositor às forças católicas e defensor da $\mathrm{AE}$ em terras latinas tem sido o CLAE. Faúndes et al. (2007) afirmam que graças às ações de oposição deste consórcio, o método pós-coito tem-se tornado conhecido e utilizado, principalmente em países como: Peru, Brasil e Chile. Dentre as ações do CLAE, Martin (2004) ressalta a realização da Conferência Regional "Derecho a la Anticoncepción de Emergencia em America Latina", no Equador, em 2002, que contou com a participação de 20 países. Esta conferência teve como principais objetivos: aumentar o conhecimento e a aceitação da AE como um método seguro e eficaz, e apelar aos legisladores das políticas públicas que apoiassem a inclusão do método nas normas oficiais dos programas de planejamento familiar dos países latinos. Antes desta conferência, apenas 10 países tinham o método da $\mathrm{AE}$ incorporado as suas normas de planejamento familiar e em 13 havia produtos registrados para tal método. Em 2004, 18 países haviam adotado oficialmente a $\mathrm{AE}$ em seus programas de planejamento familiar e 19 países contavam com produtos, para contracepção de emergência, registrados.

Diaz et al. (2003a e 2003b), assim como Pinto Costa et al. (2008), Martin (2004) e Faúndes et al. (2007), pontuam que na América Latina, como em outras regiões, são dois os principais problemas de saúde reprodutiva: gravidez não planejada que conduz ao aborto inseguro e a gravidez na adolescência. Segundo dados da OMS (apud DIAZ et al., 2003b), estima-se que 13\% das cerca de 585.000 mortes maternas por ano no mundo inteiro ocorram devido ao abortamento inseguro

Formulações específicas da AE são introduzidas no mercado constantemente, porémnem todos os programas de planejamento familiar na América Latina os fornecem. Em muitos lugares, porém a AE é, ainda, restrita aos casos de estupro.

Acreditando que informações sobre a aceitabilidade da AE poderiam auxiliar na elaboração de estratégias apropriadas para a introdução deste método em países latinos, pesquisadores se reuniram para desenvolverum estudo que pretendeu avaliar a aceitabilidade da AE na América Latina, em três países com contextos sócio-culturais e políticos diferentes: Brasil, Chile, e México. Para os pesquisadores, nestes três países, bem como na região toda, há um reconhecimento limitado sobre direitos reprodutivos e sexuais, as atitudes da sociedade para com a sexualidade são conservadoras, principalmente em relação aos adolescentes (DIAZ et al., 2003a e 2003b).

Algumas reflexões sobre o contexto destes três países trazem contribuições significativas para se pensar a AE e o cenário brasileiro dos direitos reprodutivos. Comparativamente, o poder da igreja católica e dos setores sociais conservadores são maiores no Chile e no México do que no Brasil. A $\mathrm{AE}$ é mencionada em diretrizes nacionais brasileiras tanto para o planejamento familiar quanto para o cuidado de vítimas de violência sexual, porém no Chile e no México nenhum documento oficial faz menção a este método.

$\mathrm{O}$ estudo multicêntrico, mencionado acima, selecionou os participantes a partir das seguintes categorias: potenciais usuárias dos estratos socioeconômicos médio e baixo; possíveis provedores da $\mathrm{AE}$; formuladores de políticas públicas e autoridades da área da saúde; e outras capazes de influir (influentes) no processo de disseminação da informação e provisão da $\mathrm{AE}$. Os autores trabalham os resultados da pesquisa discutindo as seguintes categorias: as percepções e o conhecimento prévio da $\mathrm{AE}$; os fatores que podem facilitar ou dificultar a introdução deste método nestes três países (HARDY et al., 2001; DIAZ et al. 2003a e 2003b).

Obstáculos similares ao acesso e uso da $\mathrm{AE}$ foram detectados nos três países, embora o peso atribuído a eles divergisse. Em geral, foram percebidas menos barreiras no 
Brasil e, mais no Chile. O México ficou em uma situação intermédia.

No Chile e no México, os participantes alegaram que a Igreja Católica e a ala direita da política fariam forte oposição à $\mathrm{AE}$, pois tal medicamento é considerado um método abortivo, que incentiva o comportamento sexual irresponsável entre os adolescentes. Esta foi uma preocupação menor no Brasil, pois os participantes acreditavam que, as barreiras brasileiras estariam mais relacionadas com $\mathrm{o}$ indivíduo do que às perspectivas e fatores sociais ou políticos.

Os participantes de todas as categorias nos três países pensavam que o prazo para a utilização da AE coloca um problema: a acessibilidade ao planejamento familiar é limitada, em parte, devido ao fato que os provedores estão sobrecarregados e, em parte, devido à burocracia em centros de saúde. Os trabalhadores da saúde e os gestores não consideram a oferta de contraceptivos como um serviço de emergência.

No Chile e no México, e, em certa medida, no Brasil, trabalhadores da saúde tinham alguma familiaridade com a $\mathrm{AE}$ ou tinham informações incompletas sobre ela. Muitos prestadores de cuidados e de autoridades dos três países comentaram que faltava a formação adequada do pessoal para aconselhar e oferecer tal método.

$\mathrm{O}$ fato de não haver produtos registrados para a $\mathrm{AE}$ no Chile e México, dificulta tanto a introdução, quanto o uso correto do método. As empresas farmacêuticas, nos dois países, não estavam interessadas em produzir um contraceptivo pós-coital com formulação específica.

Uma importante barreira detectada pelos potenciais usuários era a sua falta de conhecimentos sobre biologia reprodutiva e contracepção. Limites no conhecimento das mulheres sobre seus corpos ocasionam pouca consciência de quando estão em risco de engravidar. Alguns participantes, principalmente, potencial usuárias dos três países, manifestaram preocupações ou medo dos efeitos secundários da AE após uso prolongado.

A maioria dos participantes deste estudo apresentou atitudes positivas em relação à AE. No Brasil e no México, todas as categorias de participantes expressaram opiniões favoráveis e consideraram este método aceitável dentro de situações de emergência. No Chile, os participantes que demonstraram estas opiniões eram os adolescentes, a maioria de mulheres adultas, ativistas da saúde das mulheres, alguns médicos fornecedores, autoridades sobre os adolescentes, autoridades de saúde, membros de congresso (da esquerda), e fornecedores de cuidados para vítimas de violência sexual.

Todas as categorias de participantes alegaram que tal método ajudaria a evitar abortos induzidos. A maioria dos sujeitos da pesquisa prefere a $\mathrm{AE}$ ao aborto, e alegam que contracepção pós-coito representa uma alternativa para as mulheres, que nunca fariam um aborto, mas que desejam impedir uma gravidez após relação desprotegida.

Nos três países, os entrevistados de todas as categorias apontaram AE como um mecanismo que ajudaria a impedir as conseqüências de gravidezes não desejadas: limitaçõesnos projetos devidadosadolescentes, crianças violentadas ou abandonadas, conflitos matrimoniais, e problemas financeiros. Em todos os três países, a maioria de potenciais usuários e os fornecedores diz que as mulheres têm o direito de aprender a usar esta alternativa contraceptiva.

A opinião negativa mais freqüente, apreendida de uma minoria dos participantes do Chile e do México, era considerar a AE um método "micro-aborto". Alguns, igualmente pensaram que sua introdução estaria associada com mais riscos para a saúde do que benefícios.

No que se refere aos entrevistados brasileiros, de modo geral, estes concordaram que $\mathrm{AE}$ age evitando a gravidez; enfatizaram que o conceito de gravidez varia de pessoa para pessoa e, em função destas perspectivas individuais e/ou grupais, algumas pessoas e/ ou grupos poderão considerar a $\mathrm{AE}$ abortiva. Alguns médicos não ginecologistas, atuantes em serviços de emergência e de atenção básica (prováveis provedores), manifestaram a opinião de que o método poderia significar a indução de aborto. Até mesmo entre médicos ginecologistas a AE foi qualificada, por alguns, como "microabortivo". Apenas um médico declarou que não sabia a diferença entre $\mathrm{AE}$ e a indução do aborto, apesar de ter lido a norma técnica do MS sobre o método.

No Chile e no México, a maioria dos provedores e potenciais usuários demonstrou 
preocupação com o mecanismo de ação da AE. A maior parte dos potenciais provedores que trabalha nas clínicas do governo no Chile e alguns provedores no México, também mostraram preocupações com as implicações jurídicas da administração de tal método contraceptivo, pois consideravam o mecanismo de ação incerto.

Todos os participantes concordaram que o método era necessário, em caso de violência sexual ou incesto. Nos três países, a maioria dos participantes concordou que AE seria necessária para determinados grupos, como: mulheres jovens ou jovens casais, assim como mulheres adultas sem um parceiro estável ou com muitas crianças. Os entrevistados, também concordaram que o método era necessário em algumas situações específicas, tais como: relação sexual desprotegida ou não planejada, rompimento do preservativo, recusa do parceiro em usar um preservativo, bem como a utilização incorreta do método de abstinência periódica ou outros contraceptivos.

Para os entrevistados brasileiros, todos têm direito de saber que AE existe. Estes consideraram que no Brasil existem apenas barreiras relativas, associadas às perspectivas individuais ao uso deste método, pois a contracepção pós-coito estaria legitimada legalmente no país (pela norma do MS e pela lei do Planejamento Familiar). Para as pessoas influentes, o contexto social brasileiro é favorável à disseminação de informações e a provisão da $\mathrm{AE}$ pelos serviços de saúde. Porém os participantes declararam que apenas a existência de normas não garante o acesso ao método, é preciso criar mecanismos que acompanhem a aplicação destas normas; neste sentido as barreiras, segundo pessoas influentes e provedores, seriam as dificuldades de infraestrutura dos serviços públicos de saúde no país. Para os entrevistados, a disseminação de informação e provisão da AE será facilitada se os meios de comunicação de massa forem utilizados de maneira cuidadosa.

Nos três países, muitos participantes alegavam que a $\mathrm{AE}$ poderia causar impacto negativo sobre o comportamento sexual e contraceptivo. Para minimizar esta possibilidade, eles sugeriram que a divulgação de informações sobre tal método fosse parte de um esforço mais amplo de educação sexual. Eles também enfatizaram que a $\mathrm{AE}$ é um método a ser utilizado apenas em situações de emergência; que deve ser usado por mulheres que realmente precisam; que se evitem usos freqüentes para evitar efeitos negativos para a saúde

Participantes dos três países consideraram que a AE seria útil para mulheres em geral, portanto, deveria estar disponível a todos elas. A questão da disponibilidade foi declarada pelos sujeitos da pesquisa como parte dos direitos sexuais e reprodutivos.

A aceitabilidade do método entre os adolescentes foi particularmente elevada, independente de prévia experiência sexual ou reprodutiva. Eles sentiram que o método seria mais útil para eles do que para os adultos, especialmente para as moças mais jovens, no início da atividade sexual, pois são elas que correm o riso de serem mais expostas. Algumas jovens sentiram que a AE era mais adequada nos casos de intercurso sexual com parceiros ocasionais, quando é difícil discutir contracepção ou negociar o uso do preservativo. Os adolescentes defenderam a necessidade de difundir informações exatas sobre o método.

Segundo os participantes da pesquisa dos três países, os adolescentes enfrentam alguns obstáculos específicos, com a quase inexistência de serviços de saúde específicos para eles e a falta de informação sobre os contraceptivos. Muitos adolescentes relataram dificuldades de falar sobre a sexualidade, tanto com os pais, quanto com os adultos em geral. Também mencionaram obstáculos à utilização de contracepção levantados pelos pais, que não querem que seus filhos se tornem sexualmente ativos. De acordo com as entrevistas, os adultos têm dificuldade de informar aos adolescentes sobre a $\mathrm{AE}$, uma vez que muitos pais não conseguem falar de sexo com seus filhos. A maior parte dos adolescentes aprende sobre sexo e contraceptivos a partir de seus pares. Estes aspectos não permeiam apenas a realidade latina, segundo Schalet (2004), o comportamento sexual adolescente é visto como fora de controle, perigoso e imoral, também no debate público e político sobre saúde reprodutiva dos EUA. O medo da sexualidade adolescente embasou a recente decisão de não se oferecer o recurso do método da AE no país.

Este medo do perigo parece estar fundamentado pela realidade. As taxas de 
gravidez, nascimento e aborto permanecem as mais altas entre os adolescentes americanos, são dados que parecem confirmar a suspeita convencional que relaciona o não controle dos hormônios adolescentes a sua não capacidade de tomar decisões no âmbito da sexualidade. Porém, a autora apresenta uma realidade de saúde do adolescente, totalmente contrária à realidade norte-americana: os adolescentes da Holanda, apesar dos dois países apresentarem contextos similares em termos de saúde, educação e tecnologias reprodutivas. As adolescentes holandesas estão muito menos propensos a ficarem grávidas ou contraírem DSTs do que os adolescentes dos EUA. Quando iniciam suas vidas sexuais, os holandeses usam contraceptivos mais freqüentemente e mais eficazmente, e possuem menos parceiros sexuais, do que os americanos.

Na Holanda, há algum tempo, vige a mais baixa taxa de gravidez na adolescência, aborto e fertilidade de todo o mundo. As políticas públicas e as práticas de saúde holandesas têm, durante as últimas três décadas, promovido a aceitação da sexualidade adolescente e facilitado o seu acesso aos contraceptivos, ao invés de promover a abstinência e o medo dos potenciais perigos da sexualidade. Pais holandeses normalizam a sexualidade adolescente.

Na cultura latino-americana em geral, os pais preferem acreditar que seus filhos e filhas não se dedicam à atividade sexual, o que torna a discussão sobre sexualidade inviável no âmbito da família. Há uma dramatização da sexualidade dos adolescentes, segundo Schalet (2004), assim como ocorre nos EUA.

Retomando o estudo realizado no Brasil, Chile e México, os pesquisadores apontam que questões relacionadas ao gênero, sexo e AE foram discutidas, principalmente, por mulheres jovens e adultas, defensores da saúde e por professores. A vantagem percebida, por estes entrevistados seria de que as mulheres poderiam usar o contraceptivo sem precisar do consentimento do parceiro. Este aspecto, também se constituiu motivo pelo qual, alguns, participantes desgostaram da AE, uma vez que o método poderia reforçar o tradicional papel da mulher como responsável pela prevenção da gravidez, e poderia apoiar o comportamento reprodutivo irresponsável dos homens.

Os resultados deste estudo enfatizaram a aceitação generalizada da AE na América Latina, apesar das afirmações de que esta é uma região conservadora, fortemente influenciada pela posição da Igreja Católica em questões de reprodução e sexualidade. A necessidade da $\mathrm{AE}$ foi percebida pela maioria dos participantes, levando à conclusão de que autoridades da área da saúde têm a responsabilidade de implementar programas para a sua introdução. $\mathrm{O}$ conceito da $\mathrm{AE}$ como um método para a prevenção de aborto foi considerado uma estratégia para a introdução do método nos três países.

Especificamente,paraosentrevistados do Brasil, a AE deveria ter seu uso controlado pelos serviços de saúde; todos deveriam saber sobre o método, mas seu uso precisaria ser prescrito por um médico. Os entrevistados indicaram como essencial que os profissionais de saúde fossem capacitados para proverem a informação e o método.

Nos três países participantes, especialmente entre os potenciais fornecedores e autoridades, acredita-se que a introdução da $\mathrm{AE}$ seria mais fácil se as informações acerca do método fossem incluídas em um extenso projeto educativo sobre sexualidade e contracepção.

A partir da observação dos participantes, foi possível aos autores (HARDY et al., 2001; DIAZ et al. 2003a e 2003b) considerarem que a disseminação de informações sobre o método da AE deve ser cuidadosa e ficar a cargo dos serviços de saúde (através de programas voltados às ações educativas). Principalmente, que a contracepção do dia seguinte precisa ser dissociada da polêmica do aborto, ressaltando seu caráter contraceptivo emergencial.

Dados semelhantes aos coletados nesse estudo multicêntrico, que evolveu o Brasil, México e Chile, podem ser observados em uma pesquisa qualitativa realizada em 2004 no Greater Vancouver - Canadá (Shoveller et al., 2007). O estudo tinha como objetivo conhecer o que as mulheres pensavam sobre o uso da AE. Foram recrutadas mulheres que se auto-identificavam como asiáticas ou do sul da Ásia, e européias oriundas de diversos ambientes culturais. O recrutamento ocorreu através de anúncios publicitários em 35 lugares (centros de serviços a imigrantes, residências universitárias, clínicas de aborto, ônibus e abrigos). Os critérios de elegibilidade eram: 
viver em Vancouver, conseguir participar de uma entrevista em inglês, ter ouvido falar da AE. Inicialmente as entrevistas foram feitas com mulheres que tinham usado a AE pelo menos uma vez. Os pesquisadores também queriam incluir mulheres que ainda não tinham usado a AE, uma vez que algumas mulheres poderiam ter tido o acesso a $\mathrm{AE}$ impedido, apesar de manifestado desejo de usar tal método. Foram entrevistadas 18 mulheres de origem asiática, 16 com origem no Sul da Ásia e 18 de origem diversas (européia, aborígine, do Oriente Médio e africana). 4 participantes eram alunas internacionais, 20 imigrantes, 28 tinham nascido no Canadá (filhas de imigrantes).

Segundoas participantes, observações moralizantes baseadas em pareceres negativos sobre o comportamento sexual e a saúde reprodutiva das mulheres, que recorreram ao uso da AE, são comuns entre profissionais da área da saúde e entre outras mulheres. Estas observações (recorrentes no discurso das mulheres) constituem uma barreira potencial ao uso da anticoncepção - há o medo de ser estigmatizada como esse "tipo de mulher". Nesse estudo, a AE foi por várias vezes compreendida como um método abortivo que teria efeitos a longo prazo na saúde e fertilidade das mulheres. Essas lacunas impedem o uso, assim como lacunas no conhecimento sobre o ciclo menstrual. Os benefícios desse método são dificultados pela cultura conservadora e normas sociais. Barreiras e desvios no acesso a AE podem provocar atraso no uso do medicamento, o que pode ocasionar sua pouca eficácia.

Apesar das novas políticas canadenses destinadas a aumentar a disponibilidade da $\mathrm{AE}$, baseadas na garantia aos farmacêuticos de British Columbia da independência na prescrição da $\mathrm{AE}$, o desafio de promover acessibilidade permanece. Os resultados desta pesquisa destacam a necessidade das mulheres receberem informações que ressaltem a privacidade e a marca confidencial que envolve o acesso ao método. $\mathrm{O}$ estudo mencionado fornece indícios de quanto as forças socioculturais afetam as preferências relacionadas ao acesso e ao uso do método.

Para Pinto Costa et al. (2008), as principais barreiras que podem dificultar o acesso a AE seriam: a falta de informação, incluindo a percepção equivocada de que o método poderia ser abortivo; aspectos morais e culturais; preço dos produtos e a exigência de prescrição médica.

Um estudo (NOGUEIRA et al., 2000) realizado com estudantes do primeiro $\left(1^{\circ}\right)$ ano de um curso de medicina do interior de São Paulo, em 1999, revelou dados significativos sobre os mitos que envolvem a questão do uso da AE. Foram entrevistados 91 estudantes, sendo 31 do sexo feminino e 60 do sexo masculino. $\mathrm{O}$ inquérito mostrou que o método é pouco conhecido e os estudantes que conheciam apresentavam dúvidas sobre o seu mecanismo de ação e efeitos colaterais. Entre os entrevistados (de ambos os sexos) que usariam o método, a maioria acreditava ser o método abortivo e apresentava dúvidas quanto aos efeitos colaterais.

A contracepção pós-coito é ainda um método muito envolto em mitos entre os profissionais de saúde. Há uma representação de que a contracepção de emergência é perigosa, sendo merecedora de cuidados especiais na sua disponibilização.

Segundo Simods e Elletertson (2004), legal e ideologicamente, contracepção e aborto dividem uma história parecida e ambos estão associados com o tabu da sexualidade feminina. Essa percepção não é privilegio apenas em países latinos, para as autoras mencionadas se as mulheres nos EUA tivessem acesso ao método da AE, metade das gravidezes não planejadas e dos abortos seria evitada.

Estudos levantados por Simods e Elletertson (2004), indicam que profissionais de saúde na Europa e EUA têm um alto conhecimento a respeito dos contraceptivos de emergência, mas têm reservas quanto à sua oferta. Muitos acham que facilitando a acesso a AE, as mulheres podem deixar de usar contraceptivos durante o ato sexual e assim, adquirirem DSTs.

Pinto Costa et al. (2008) apontam que essa preocupação dos profissionais quanto ao potencial negativo que a informação mais ampla sobre o método poderia causar sobre o uso regular de anticoncepcionais e de preservativos, constitui-se numa das maiores barreiras para a democratização do acesso a AE. Para esses autores, não há estudos (internacionais ou nacionais) que comprovem esta preocupação. Sendo assim, a organização não-governamental, Bemfam, realizou 
em 2004 uma pesquisa com o objetivo de comparar duas estratégias de acesso a $\mathrm{AE}$ no contexto brasileiro - "informação com entrega antecipada do método, e somente informaçãoconsiderando o padrão de uso da contracepção pós-coito e os efeitos do acesso a este método sobre o uso regular de anticoncepcionais, incluindo preservativos". (p: 56)

O estudo recrutou 823 voluntárias (com idades entre 18 e 49 anos) em seis clínicas de saúde reprodutiva da BEMFAM, nos estados do Rio de Janeiro, Ceará, Maranhão, Paraíba, Pernambuco e Rio Grande do Norte, no período de agosto de 2004 a janeiro de 2005.

As entrevistadas foram divididas em dois grupos: grupo medicado (informação e entrega antecipada para 419 mulheres) e grupo controle (informação para 404). Todas as mulheres receberam informações sobre a AE, uso de preservativos e prevenção de DSTs e material impresso sobre o método pós-coito. As mulheres do grupo controle receberam, também, dois kits contendo preservativo masculino. As mulheres do grupo medicado receberam dois kits, compostos cada um por duas doses de produto específico para AE e por um preservativo masculino.

O estudo teve duração de oito meses e 407 mulheres (215 do grupo medicado e 192 do grupo controle) completaram as fases deste (compareceram as duas consultas agendadas no ato da entrega dos kits). Pinto Costa et al. (2008) chamam a atenção para alguns resultados do estudo. Apesar de terem informação e acesso gratuito a AE, a maioria dos casos (61\%) não fez uso da AE. Entre os $39 \%$ de mulheres que utilizaram o método, $57 \%$ era do grupo medicado e $18 \%$ do grupo controle. A entrega antecipada favoreceu o uso antecipado tendo em vista que uso mais precoce foi entre as mulheres do grupo medicado, o que garante maior eficácia ao método. Quanto ao uso de métodos anticoncepcionais regulares, verificou-se um aumento significativo destes no grupo medicado (inclusive de preservativos, que passou de $63 \%$ para $68 \%$ ) e uma redução não significativa no conjunto dos métodos do grupo controle.

Para Pinto Costa et al. (2008) os resultados deste estudo confirmam dados de outros estudos realizados na China, EUA, e Índia. Nestes estudos, a disponibilização antecipada da $\mathrm{AE}$ não reduziu as taxas de gravidez não planejada, apesar da maior freqüência de uso e do uso mais precoce com a entrega antecipada; não houve aumento de DSTs nem de ocorrências de relações sexuais desprotegidas; nãohouvemudançano padrão do uso de métodos anticoncepcionais; a utilização de preservativo foi similar entre mulheres que receberam a $\mathrm{AE}$ antecipadamente e as que não receberam o método. A preocupação dos profissionais não foi confirmada no estudo promovido pela BEMFAM e nem pelos estudos internacionais. Uma questão relevante, porém, precisa ser considerada: o não uso da $\mathrm{AE}$ pode estar associado à negação das situações de risco (NELSON apud PINTO COSTA et al.; 2008). A não redução das taxas de gravidezes indesejadas pode estar ligada com o não reconhecimento, das mulheres, de situações de risco: por acreditarem estar fora do período fértil ou por realizarem o coito interrompido.

\section{Conclusão}

Segundo Pinto Costa et al. (2008) o acesso a informação e a $\mathrm{AE}$ devem ser ampliados. Com orientação sistematizada e consistente as mulheres podem fazer uso da contracepção pós-coito, quando necessário, sem abandonar o uso de anticoncepcionais regulares e a proteção às DSTs.

Uma questão é latente no debate sobre a pílula do dia seguinte: como ampliar o acesso a informações sobre o método, bem como o proporcionar que as mulheres tenham acesso ao medicamento sempre que desejar nos serviços públicos de saúde? Sabe-se hoje que o medicamento é vendido cotidianamente nas farmácias sem controle algum, sem prescrição ou acompanhamento médico, podendo inclusive trazer prejuízo à saúde das jovens e mulheres. No quadro traçado sobre a AE, pesquisas identificam a importância da mídia para a democratização das informações, tanto quanto para a desconstrução destes mitos e barreiras sobre tal método.

\section{Referências}

AVILA, M. B. e CORRÊA, S. O movimento de saúde e direitos reprodutivos no Brasil: revisitando percursos. In: GALVÃO, L. e DÍAZ, J. Saúde Sexual e Reprodutiva 
no Brasil. São Paulo: Hucitec; Population Council, 1999. pp: 165-179.

BOZON, M. Sociologia da Sexualidade. Rio de Janeiro: Editora FGV, 2004.

CASTILlO, C. D. Voces em Emergencia: El discurso conservador y la pildora del dia después. Santiago, Chile: FLASCO, 2006.

\section{CONFERÊNCIAINTERNACIONALSOBRE} POPULAÇÃO E DE $\neg$ SENVOLVIMENTO, 1994, Cairo, Egito. Relatório final. [S.1.]: CNPD; FNUAP, 1994.

CONSELHO FEDERAL DE MEDICINA. Resolução N $^{\mathbf{1}} \mathbf{1 8 1 1}$ de 14 de dezembro de 2006: Normas Técnicas Para A Utilização Da Contracepção De Emergência. Diário Oficial da União. Edição 12 de 17/01/2007.

Brasil. Constituição da República Federativa do Brasil, Congresso Nacional, Brasília, 1988

CORREA, S., ALVES, J. E. D., JANNUZZI, P. M.. Direitos e Saúde Sexual e reprodutiva: marco teórico-conceitual e sistema de indicadores. In: CAVENAGHI, S. (Org). Indicadores municipais de saúde sexual e reprodutiva. Rio de Janeiro: ABEP, Brasília: UNFPA, 2006.

CORRÊA, S. e PETCHESKY, R. Direitos Sexuais e Reprodutivos: uma perspectiva feminista. In: PHISIS: Revista de Saúde Coletiva, Rio de Janeiro, 6(1/2), 1996. pp: 147-177

COSTA, A. M. et al. Planejamento Familiar: autonomia das mulheres sob questão. In: Revista de Saúde Materno-Infantil, Recife 6 (1): 75-84, jan/mar, 2006.

DÍAZ, S., HARDY, E., ALVARADO, G., EZCURRA, E.. Acceptability of emergency contraception in Brazil, Chile, and Mexico. 1 Perceptions of emergency oral contraceptives. In: Cadernos de Saúde Pública, Rio de Janeiro, 19(5), set-out, 2003a. pp: 1507-1517

DÍAZ, S., HARDY, E., ALVARADO, G., EZCURRA, E.. Acceptability of emergency contraception in Brazil, Chile, and Mexico.
2 - Facilitating factors versus obstacles. In: Cadernos de Saúde Pública, Rio de Janeiro, 19(6), nov-dez, 2003b. pp: 1729-1737

FAÚNDES, A., TÁVARA, L., BRACHE, V., ALVAREZ, F.. Emergency Contraception under Attack in Latin America: Response of the Medical Establishment and Civil Society. In: America Reproductive Health Matters, Volume 15, Issue 29, May 2007. pp: 130-138

FIGUEIREDO, R. Contracepção de Emergência no Brasil: necessidade, acesso e política nacional. In: Revista de Saúde Sexual e Reprodutiva, IPAS, $n^{\circ} 13$, setembro de 2004. Formato Eletrônico em http://www. ipas.org.br

FIGUEIREDO, R. e PENÃ, M. Promoção da contracepção de emergência no Brasil associada à prevenção da AIDS. In: Ações de Advocacy em Saúde e Direitos Reprodutivos, Brasília; Agende, 2002.

GALVÃO, L. Saúde sexual e reprodutiva, saúde da mulher e saúde materna: a evolução dos conceitos no mundo e no Brasil. In: GALVÃO, L. e DÍAZ, J. Saúde Sexual e Reprodutiva no Brasil. São Paulo: Hucitec; Population Council, 1999. pp: 165-179.

GOMES COSTA, S. Proteção Social, Maternidade Transferida e Lutas pela Saúde Reprodutiva. In: Revista Estudos Feministas. Universidade Federal do Rio de Janeiro, v.10, jul/dez, 2002. pp: 301-323.

HARDY, E. et al. Anticoncepção de emergência no Brasil: facilitadores e barreiras. In: Cadernos de Saúde Pública, Rio de Janeiro, 17(4), jul-ago, 200. pp: 1031-1035.

HEILBORN, M. L.. Gênero, Sexualidade e Saúde. In: SILVA, D.P.M. (Org). Saúde, sexualidade e reprodução: compartilhando responsabilidades. Rio de Janeiro: Faculdade de Serviço Social/UERJ. 1997. pp: 101-111.

HEILBORN, M. L.. Experiências da Sexualidade, Reprodução e Trajetórias Biográficas Juvenis. In: HEILBORN, M. L. et al. (Orgs). O aprendizado da sexualidade: reprodução e trajetórias sociais de jovens brasileiros. Rio de Janeiro: Garamond e 
MARTIN, A. La anticoncepción de emergencia em América Latina y el Caribe. In: Revista Panamericana de Salud Pública/ Pan American Journal of Public Health. 16(6), 2004. pp: 424-431.

MEULDERS, D. etal.. Trabalho e Maternidade na Europa, Condições de Trabalho e Políticas Públicas. In: Cadernos de Pesquisa. São Paulo: Fundação Carlos Chagas, v.37, n¹32, setembro/dezembro, 2007. pp: 611-640.

\section{MINISTÉRIO DA SAÚDE - Cartilha de} Direitos Sexuais e Reprodutivos: uma prioridade de governo. 2005.

\section{MINISTÉRIO DA SAÚDE - Marco Teórico}

Referencial: Saúde Sexual e Reprodutiva de Adolescentes e Jovens. (versão preliminar), MS: Secretaria de Atenção à Saúde, Departamento de Ações Programáticas Estratégicas, 2007.

MINISTÉRIO DA SAÚDE/ Secretaria de Atenção a Saúde/ Departamento de Ações Programáticas e Estratégicas - Nota Técnica sobre Anticoncepção de Emergência. 2006.

MINISTÉRIO DA SAÚDE - Política Nacional de Atenção Integral a Saúde da Mulher: Princípios e Diretrizes. 2004a

MINISTÉRIO DA SAÚDE - Política Nacional de Atenção Integral a Saúde da Mulher: Plano de Ação 2004-2007,Brasilia, 2004b.

MINISTÉRIO DA SAÚDE / Secretaria de Política de Saúde / Área Técnica de Saúde da Mulher. Coords: Nelson Cardoso de Almeida e Regina Coeli Viola. Assistência em Planejamento Familiar: Manual Técnico. $4^{\mathrm{a}}$ edição. Série A: Normas e Manuais Técnicos; no 40, Brasília, 2002.

MINISTÉRIO DA SAÚDE. PORTARIA 144, de 20 de novembro de 1997.

MINISTÉRIO DA SAÚDE. PORTARIA 48, de 11 de fevereiro de 1999

MINISTÉRIO DA SAÚDE. LEI 9263 de 1996
NOGUEIRA, A. A. et al. Anticoncepcionais de emergência: por que não usar? In: Medicina, Ribeirão Preto, 33, jan./mar. 2000. pp: 60-63.

OSIS, M. J. D. et al. Atenção ao planejamento familiar no Brasil hoje: reflexões sobre os resultados de uma pesquisa. In: Cadernos de Saúde Publica, 22(11), nov. 2006. pp: 24812490.

OSIS, M. J. D.. Pesquisa sobre Planejamento Familiar. In: RIOS-NETO, E. L. G. (org). A população nas políticas públicas: gênero, geração e raça. Brasília: CNPD: UNFPA, 2006.

PINTO COSTA, N. F., et al. Acesso a anticoncepção de emergência: velhas barreiras e novas questões. In: Revista Brasileira de Ginecologia e Obstetrícia, 2008. pp: 55-60.

SAITO, M. I. e LEAL, M. M.. Adolescência e contracepção de emergência: Fórum 2005. In: Revista Paulista de Pediatria, 25 (2), 2007. pp:180-186.

SCHALET, A. Must we fear adolescent sexuality? In: Medscape General Medicine, 6(4), 2004. <http://www.medscape.com/ viewarticle/494933>

SHOVELLER, J., CHABOT C., SOON J. A., LEVINE M. Identifying Barriers to Emergency Contraception Use Among Young Women from Various Sociocultural Groups in British Columbia, Canada. In: Perspectives on Sexual and Reproductive Health, 39(1), 2007. pp:13-20

SIMONDS, W. e ELLERTSON, C.. Emergency contraception and morality: reflections of health care workers and clients. In: Social Science \& Medicine, 58, 2004. pp: 1285-1297.

SORJ, B.; FONTES, A.; MACHADO, D. C. Políticas e Práticas de Conciliação entre Família e Trabalho no Brasil. In: Cadernos de Pesquisa. São Paulo: Fundação Carlos Chagas, v.37, no132, setembro/dezembro, 2007. pp:573-594.

VIEIRA, E. M. Políticas Públicas de 
contracepção no Brasil. In: BERQUO, E. (Org.) Sexo e Vida: panorama da Saúde reprodutiva no Brasil, Campinas: Unicamp; 2003. pp. 96-151.

SUWWAN, L.. Ministério amplia a distribuição Gratuita da pílula do dia seguinte. In: Folha de São Paulo, sucursal de Brasília, 14/02/2005.

Endereço para Correspondência:

Profa Rozana Aparecida de Souza

Curso de Serviço Social

rozana.souza@foa.org.br

Centro Universitário de Volta Redonda

Campus Três Poços

Av. Paulo Erlei Alves Abrantes, nº 1325 ,

Três Poços - Volta Redonda / RJ

CEP: 27240-560 